ISSN: 0213-2087 eISSN: 2444-7080

DOI: https://doi.org/10.14201/shhc2021397392

\title{
ESPAÑA Y LA BATALLA DE ANNUAL EN EL POEMA DE DHAR OUBARRAN. (EPOPEYA POÉTICA RIFEÑA DE 1921)
}

\section{Spain and the Annual Battle in the Dhar Oubarran poem (1921 poetic epic of the Rif)}

\author{
Mohamed ABRIGHACH \\ Universidad Ibn Zohr-Agadir \\ m.abrighach@uiz.ac.ma \\ https://orcid.org/0000-0003-4916-5941
}

RESUMEN: En este artículo se intenta estudiar la visión local que se tuvo de la batalla de Annual y de los españoles en El Poema de Dhar Oubarran. El discurso de la alteridad que este poema encierra no se basa en los prejuicios denigratorios, sino en los comportamientos y acción llevada por España en el campo de batalla. En este sentido, se insiste, por un lado, en la facilidad con que los combatientes rifeños triunfaron usando armas muy convencionales, y, por otro, en la denigración del papel traidor desempeñado por los llamados «amigos de España», en su apoyo a la ocupación colonial y la correspondiente exaltación de la participación de la mujer en los campos de batalla aportando ayuda a la resistencia. A ello se añade, la dimensión brutal y violenta de los bombardeos de la aviación y el sentimiento trágico con que la voz poética vivió la destrucción provocada por ellos.

Palabras clave: Batalla de Annual; España; El Rif; poesía popular.

ABSTRACT: This article tries to study the local vision of the battle of Annual and the Spanish in the Poem of Dhar Oubarran. The discourse of otherness that it contains is not based on denigrating prejudices, but on the behaviors and actions 
carried out by Spain on the battlefield. In this sense, it insists, on the one hand, on the ease with which the Rif fighters triumphed using very conventional weapons, and, on the other, highlights the denigration of the treacherous role played by the so-called "friends of Spain", in their support for the colonial occupation and the corresponding exaltation of the participation of women in the battlefields contributing aid to the resistance. Added to this is the brutal and violent dimension of the aviation bombings and the tragic feeling with which the poetic voice experienced the destruction caused by them.

Key words: The War of Annual; Spain; The Rif; popular poetry.

\section{INTRODUCCIÓN}

La batalla de Annual y las campañas que la acompañaron antes y después de 1921 dieron lugar a uno de los ciclos literarios más significativos en las letras españolas después del de la Guerra Civil: el ciclo bélico del desastre de Annual. Trascendencia que adquiere en razón, primero, del singular significado que adquirieron los acontecimientos ocurridos entonces en la historia contemporánea de España y, segundo, de ser una coartada para volver sobre el tema de la memoria histórica en una relectura intrahistórica del pasado y de la acción de los protagonistas que vivieron la contienda bélica en el corazón del Rif. Hablar de un ciclo y equipararlo con el de la Guerra Civil remite a la existencia de una inmensa y cada vez más rica narrativa cuyos autores, ya militares, ya escritores o periodistas, vivieron la experiencia bélica en su momento, protagonizaron algunas de sus acciones o las recrean solamente desde el presente con finalidades ideológicas y estéticas diferentes y contradictorias ${ }^{1}$.

Pese a que, en Marruecos, en general, y en el Rif, en particular, la batalla de Annual se considera como un hito histórico en la lucha nacionalista contra el colonialismo español, no se benefició, ni se ha beneficiado aún, de una meritoria atención historiográfica ni literaria, prueba a buen seguro de que los marroquíes tienen todavía no pocas dificultades y serias reservas de autocensura en emprender una libre y objetiva lectura de la historia contemporánea del Marruecos tanto colonial como poscolonial. La batalla de Annual es un ejemplo de esa "memoria prohibida»" porque sigue siendo un tema sensible en clave política ya que la actuación colonial española y la represión de la llamada República del Rif se llevó a cabo, aparte del apoyo francés, con el beneplácito tácito o implícito del poder central del sultán. En lo que a narración memorialista o autobiográfica se refiere, tenemos tan solo las

1. Cf. Carrasco González, Antonio: Historia de la novela colonial hispanoafricana. Madrid: Sial, 2008, pp. 95-197.

2. KRafFt, Raphael y Roux, Charlotte: "Abdelkrim, une mémoire interdite» (documental), France culture, 2012. Disponible en: https://www.franceculture.fr/emissions/la-fabrique-de-l-histoire/ une-autre-histoire-du-maghreb-au-xxeme-siecle-24-abdelkrim-une 
memorias del líder, Abd el-krim, que han sido traducidas y recogidas tardíamente 3 , y de algún que otro colaborador o protagonista ${ }^{4}$. Otro tanto pasa con la ficción literaria en la que notamos, según nuestro modesto conocimiento, una visible ausencia de la ficcionalización histórica de Annual y de las campañas coloniales españolas, salvo algunas excepciones ${ }^{5}$. El único texto relacionado directamente con Annual del que disponemos hasta el día de hoy pertenece a la cultura popular y fue producido a la vez que cantado por trovadores locales en plena acción contra la presencia española. Es El Poema de Dhar Oubarran ${ }^{6}$, que adquiere trascendencia inédita por tres factores: la proximidad emocional en la vivencia de la guerra, la verosimilitud narrativa en el relato de los hechos ocurridos en la misma y la apología entusiástica a la vez que trágica de la resistencia nacionalista y anticolonial. En este presente artículo intentaré poner de relieve la representación que se lleva a cabo en este poema de España y de la batalla de Annual, no sin hacer una presentación tanto formal como de contenido del mismo poema en un intento de su contextualización general. Debo subrayar que mi perspectiva de análisis es esencialmente literaria y, por consiguiente, he prescindido del contexto histórico en que se escribió el poema por la simple razón de que fue amplia y definitivamente estudiado por Akoudad en un largo capítulo titulado «Epopeya de Dhar Oubarran y contenido histórico» ${ }^{7}$. Para más información sobre la versión marroquí de cómo se vivieron en el Rif los acontecimientos de Annual de 1921 son recomendables las memorias de Abd del-krim ${ }^{8}$ y los estudios de Zakia Daoud ${ }^{9}$, Germain Ayache ${ }^{10}$,

3. Roger Mathieu, J.: Mémoires d'Abd-el-Krim. París: Librairie des Champs-Elysées, 1927 (Versión árabe, Mohamadiyya: Imprenta Fedala, 2005). Ben AbDelkarim KhatTabi, Mohamed: Mémoire de La Réunion (versión árabe y francesa). Rabat: Editions Buregregue, 2017). Es una versión doble, en árabe y en francés, con una presentación y comentario de Azzouzi Abdelhamid, Ounia Mohamed, Raiss Abdelhamid, María Rosa de Madariaga y René Gallissot. La traducción al francés fue de Touhami El Azemmouri.

4. OMAR El KaDI, Mohamed: El león del Rif. Mohammad Abdelkrim Al Khattabi. Memorias sobre la guerra del Rif (en árabe). Tetuán: Impr. Dispress, 1979.

5. Beroho, Ahmed: Abdelkrim, Le lion du Rif. Tánger: Edictions Corail, 2003; Bouissef ReKKAB, Mohamed: El dédalo de Abdelkrim. Granada: Port-Royal, 2008. Ouriaghu, Mostafa: Puertas de la madrugada (en árabe). Casablanca: Centro Cultural Árabe, 2016.

6. En este artículo nos basamos en la versión ofrecida por Mohamed El OuAL y Mohamed AKOUDAD en Epopeya de Dhar Oubarran, la canción de la resistencia rifeña (en árabe), Rabat: Imp. Al Manahil, 2007, pp. 221-226. Los versos traducidos que se citan y utilizan en este artículo corresponden a esta versión.

7. AKoudad, Mohamed y El Ouali, Mohamed, op. cit., pp. 63-158.

8. Ben Abdelkarim Khattabi, Mohamed: Mémoire de La Réunion. op. cit.

9. Daoud, Zakia: Abdelkrim, une épopée d'or et de sang. Casablanca: La Croisée des Chemins, 2020.

10. AYACHE, Gremain: Les origines de la Guerre du Rif. Rabat: SMER, 1990. 
Mimoun Acharqi ${ }^{11}$, el último libro póstumo de Jorge M. Reverte ${ }^{12}$ y también la detallada recopilación bibliográfica de Mustapha Allouh ${ }^{13}$ sobre el tema.

\section{EL POEMA DE DHAR OUBARRAN: FORMA Y CONTENIDO}

Dada la escasa crítica sobre la poesía popular del Rif ${ }^{14}$, no se ha hecho de ella hasta el momento una rigurosa y objetiva tipología temática o genérica, pese a que comparte no pocas similitudes con la producida en zonas en que se habla amazigh, tanto en el resto de Marruecos como en Argelia y demás países. Existen al respecto todavía mucha polémicas y diferencias en cuanto al empleo de conceptos y categorías. En todo caso, por independencia de taxonomías de naturaleza tanto genérica (izri/izran, taquessist y tanin) como temática (ameeqeb o ręrur) satírica, (rhoua) amorosa, (jemmad), etc.) que propone Zizaoui ${ }^{15}$ podemos considerar $E l$ poema de Dhar Oubarran como una especie de cantar o canción de larga extensión, el único texto poético de esta naturaleza que nos llega por vía de la tradición oral de los imediazen, los juglares locales del Rif.

El poema ha sido considerado por todos los estudiosos como el paradigma de la poesía de la resistencia ${ }^{16}$ porque fue cantado en su momento fundamentalmente para describir los avatares de la guerra y la correspondiente lucha de los rifeños contra la presencia colonial española cantando las gestas heroicas locales contra el enemigo no sin dejar constancia de lo trágico que fue la contienda para las dos partes en liza, continuando así una tradición oral que viene de años atrás relacionados, en su mayoría, con los anteriores conflictos bélicos con España. Por eso, el poema es, por una parte, un fiel reflejo de la memoria común y colectiva, y, por otra, un inédito documento histórico que recoge en prisma emocional y poético, aunando canto y música, la visión local y vívida de la batalla de Annual en la que

11. AcharQi, Mimoun: Mohamed Abdelkrim El Khattabi: l'emir guerillero. Salé: Impr. Beni Isnassen, 2003

12. Martínez Reverte, Jorge: El vuelo de los buitres: El desastre de Annual y la guerra del Rif. Madrid: Galaxia Gutenberg, 2021.

13. Allouh, Mustapha: Le Rif face aux visés coloniales (1921-1927). Casablanca: Fondation Le Roi Abdel Aziz Al Saoud, 2004.

14. Cf. Biarnay, S.: "Notes sur les chants populaires du Rif», Les Archives berbères (1915-1916), Fasc. 1, 2. ${ }^{a}$ edición, Rabat, Al Kalam, 1987. ChariQ, Abdellah: "Introducción a la problemática de la literatura amazigh en el Rif». En: Problemáticas y manifestaciones de la cultura en el Rif (en árabe). Nador: Impr. Imperial (Rabat), 1994, pp. 59-66. ZızAoui, Abdelmottaleb: «La poésie orale au Rif: les spécificités esthétiques pour une définition du sous-genre poétique». En: Djelaou Mohamed (dir.): Actes du 3eme colloque International sur La problématique des Genres Littéraires Amazighes: Définitions, Dénominations et Classifications. Bouira: Université Akli Mohand Oulhadj, 2014, pp. 81-96

15. Zizaoui, Abdelmottaleb, op. cit. pp. 81-96.

16. MejJouki, Abdessamad: La resistencia rifeña a través de la poesía amazigh del Rif. Caso de Dhar Oubarran. (en árabe). Rabat: Publicaciones del Alto Comisionado para los Antiguos Combatientes y Miembros del Ejército de Liberación, 2014. Akoudad, Mohamed y El Oual, Mohamed, op.cit. 
los rifeños consiguen, aunque sometidos y pacificados después, una victoria inédita y aparatosa que hizo horror en España y tuvo fama universal.

El título del poema hace referencia a Dhar Oubarran, el Monte Abarrán, un topónimo que alude a un monte o colina que existe a pocos kilómetros de Annual y enfrente del famoso monte Kama, situado en la localidad o cabila de Temsaman, epicentro de los principales acontecimientos de 1921. Es en este monte donde el ejército español sufre su primer descalabro en tierra del Rif y lo siguen otros, según indica el mismo texto, como Igueriben, Sidi Dris, Annual, Drius y Monte Arruit, etc., lugares que, en su mayoría, eran fuertes o fortines militares que los españoles fueron construyendo durante su sucesiva ocupación territorial de la zona. El poema habla, en este sentido, de todas las luchas locales relacionadas con Annual o la batalla de Annual, razón más que lógica para denominarlo cantar de Annual y no de Dhar Oubarran.

Si bien El Poema de Dhar Oubarran sigue necesitando todavía un estudio más exhaustivo, las aportaciones de El Ouali y Akoudad $^{17}$, y también de Serroual ${ }^{18}$ y Mejjouki ${ }^{19}$ son muy significativas y arrojan bastante luz por primera vez sobre el trasfondo histórico del texto así como sobre sus diferentes dimensiones formales de índole lingüística, poética y estética. Al mismo tiempo que remito el lector a los estudios de los mencionados autores, me conformo con resumir para no reiterar roturadas evidencias, algunos de los aspectos más sobresalientes del poema, un acote formal y literario imprescindible para un acertado análisis de la representación de la batalla de Annual y de lo español que en ella está encerrada, el principal objetivo del presente ensayo.

El Poema de Dhar Oubarran es el texto más popular de todo el Rif, entendiendo por el Rif el concebido por los lingüistas y los antropólogos. Lo es por partida doble. El cantar es anónimo y creación de todo el pueblo en la medida en que su presumible autoría recae en la voz colectiva, bien de gentes de a pie o de los imediazen, una especie de poetas populares que vivían del canto y la música en bodas y festividades colectivas. Por eso, "es difícil hablar de una versión original y auténtica puesto que el texto viaja y es sometido, en consecuencia, a mutaciones por exceso o defecto, a truncamientos o a adiciones más o menos apócrifas» ${ }^{20}$. Mejjouki recoge casi una quincena de versiones distintas ${ }^{21}$ y la más completa que tenemos hoy en día, la presentada por Akoudad y El Ouali, no pretende ser definitiva. Así es como lo afirman los dos autores:

17. El Oual, Mohamed y AKoudad, Mohamed: op. cit.

18. Serroual, Mohammed: "L'épopée de Dhar Oubarran. Episode de la guerre du Rif (1921). Transcription, traduction et analyse de fragments». En: Forum d'Imerqane. Patrimoine en partage. Actes du 1 Festival des Cultures Immatérielles Méditerranéennes de Nador. Oujda: Agence de l'Oriental, 2007, pp. 108-143.

19. MejJouki, Abdessamad, La resistencia rifeña a través de la poesía amazigh del Rif. Caso de Dhar Oubarran. (en árabe), op. cit.

20. Serhoual, Mohammed: op. cit., p. 108.

21. MejJouki, Abdessamad. op. cit. pp. 85-124 
Presentamos aquí un texto no definitivo porque no tomamos en consideración todas las versiones y subestimamos no pocas series de versos. Su pobreza estética y su poca vinculación con el contexto histórico nos llevó a considerarlas como adiciones tardías. Esto no significa que el texto presente sea definitivo o que nadie pueda presentar al lector otra versión ${ }^{22}$.

La segunda vertiente de la popularidad de El poema de Dhar Oubarran no tiene que ver con su genealogía creadora anónima, sino con su posterior circulación y transmisión en la zona. Sigue siendo el poema más conocido entre la generación que vivió la época de la guerra contra España. Después de la independencia de Marruecos fue cantado por los mejores de los cantautores y grupos musicales del Rif, desde Nador hasta Alhucemas. Este lugar privilegiado que ocupa en la cultura local rifeña procede del hecho de ser el único texto de la memoria colectiva y de su lucha contra la invasión extranjera, y, sobre todo, deriva de tener como tema de fondo la batalla de Annual que fue un desastre para España y objeto de gran orgullo local y nacional, amén de su irrecusable universalidad.

Haciéndose eco de los testimonios de algunos ancianos, Akoudad nos informa de que El poema de Dhar Oubarran debió de tener casi mil versos ${ }^{23}$, mientras que Serhoual piensa que el texto integral está compuesto por más de 160 versos $^{24}$. La más actualizada y cotejada versión, la de Akoudad y El Ouali, contiene tan solo 138 versos $^{25}$. Como es común en la poesía popular del Rif, la constitución rítmica de El Poema de Dhar Oubarran se basa principalmente en las normas métricas de Rmizan Ralla Buya ${ }^{26}$, basadas en una medida de doce sílabas con rimas a veces consonantes y otras asonantes. Los versos son mayoritariamente alejandrinos, pero con cesura en medio que da lugar a dos hemistiquios independientes que a veces, pero no siempre, llevan rimas, de igual modo, consonantes o asonantes. Si bien en los diferentes izran rifeños la configuración estrófica consiste básicamente en pareados y a veces cuartetos, el poema que estamos presentando no tiene una configuración estrófica precisa; los versos se estructuran formalmente en series de más de cuatro versos, frecuentemente de seis, en virtud de la permanencia de la rima, sea consonante o asonante, y de otros mecanismos como las aliteraciones y los paralelismos léxico-sintácticos. Esta estructura rítmico-métrica no es típica del Rif porque la comparte con la tradición de la poesía popular tanto medieval

22. AKoudad, Mohamed y El Oual, Mohamed: op.cit., p. 6.

23. AKoudad, Mohamed: "Contenido histórico de la epopeya de Dhar Oubarran". En: AKOuDAD, Mohamed y El Ouali, Mohamed: Epopeya de Dhar Oubarran, canción de la resistencia rifeña. Rabat: Al Manahil, 2007, p. 56.

24. Serhoual, Mohammed: op. cit., p. 109.

25. AKoudad, Mohamed y El Ouali, Mohamed: op.cit., pp. 221-226.

26. MoutAwAKkil, Mourad: "La imagen del militar español en la poesía oral rifeña». En: AmaHJOUR, Aziz (coord. y ed.). Sobre literaturas orales y literatura comparada. Madrid: Diwan Mayrit, 2020, pp. $157-171$. 
como mediterránea, una vertiente universal en palabras de El Ouali ${ }^{27}$ que lleva a Serhoual a asociar en clave comparativa y con razón El poema de Dhar Oubarran con La Chanson de Roland francés ${ }^{28}$.

Ha sido habitual considerar como epopeya al Poema de Dhar Oubarran por ser su principal, cuando no único contenido, la narración de las acciones bélicas llevadas a cabo con coraje y osadía por parte de los luchadores rifeños contra la ocupación de las tropas españolas del Rif en 1921. Según El Ouali, siempre es posible considerar a este texto poético como poema épico, pero su realidad es distinta porque "no responde a los principios narrativos vinculados con la epopeya» ${ }^{29}$, razón por la cual concluye, afirmando con pertinencia, que «el poema tiene su lógica propia y es singular cultural e históricamente» ${ }^{30}$. La composición de El Poema de Dhar Oubarran es mucho más compleja. Uno de sus rasgos más significativos y explicadores a buen seguro de su renombre y popularidad en el Rif, es su transversalidad escrituraria en que se entreveran indistinta y fácilmente géneros, subgéneros, registros, estilos y tonos. El género épico, con su doble vertiente tanto narrativa como histórica, coexiste con otro más dominante, el lírico, que convierte la historia en discurso, el «él» en "yo» y lo público en privado a través principalmente de un doble tono, elegíaco y trágico a la vez. Este último lo resumen los dísticos que se repiten más de una vez al principio del poema. A todo ello se añade la lamentación con que son expresadas las pérdidas de seres queridos y el horror de la guerra. La vertiente dramática se confronta, a su vez, con un canto optimista y eufórico del amor, la naturaleza, la necesidad de la música, y, en una palabra, de la vida. El estilo acompaña esta diversidad a la perfección. Aparte del registro narrativo, domina un lato y craso descriptivismo informativo y verosímil tan intrínseco del documento histórico; se yuxtaponen también monólogos y diálogos, y prevalece, sobre todo, una considerable poeticidad lírico-formal que se expresa mediante, entre otros, los mecanismos de la analogía plástica, la metáfora y la comparación principalmente que, según El Ouali, son propias de «la poesía moderna ${ }^{31}$.

Termino este apartado con un inciso sobre literatura comparada. Serhoual asocia, como se ha mencionado páginas atrás, El Poema de Dhar Oubarran con el poema medieval francés La Chanson de Roland, en razón tan solo de la similitud en la estructura métrico-rítmica relacionada con el uso de los versos alejandrinos. Al contrario, quien esto escribe procedería a emparentar el cantar rifeño de Dhar Oubarran con El cantar de Mío Cid, también medieval pero perteneciente a un espacio simbólico literario más próximo, el español, que tuvo siempre relaciones de transculturación con el imaginario norteafricano e islámico a lo largo de la historia.

27. El Oudi Mohamed: «Lectura retórica de la epopeya de Dhar Oubarran». En: Akoudad, Mohamed y El Oual, Mohamed: op. cit., p.199.

28. Serhoual, Mohammed: op. cit., p.120.

29. El Ouali, Mohamed: ibid, p. 208

30. Ibidem.

31. Ibid, p. 212 
Dicho, en otros términos, El poema de Dhar Oubarran es el Mío Cid a la inversa, del sur y del Rif en particular. Lo es, en mi modesta opinión, por las siguientes razones de naturaleza formal y temática a la par: 1) por usar una semejante estructura rítmicométrica, basada en versos alejandrinos, con cesura y rima asonante o consonante, y también igual composición por serie de versos y no por estrofas; 2) por ser el contenido, aparte de su naturaleza esencialmente épico-bélica, una lucha de moros y cristianos por la dominación de unos por otros o la resistencia de unos contra otros también; 3) por el protagonismo actancial que recae en Abd el-krim, líder de Annual, y el Cid Campeador, Rodrigo Díaz de Vivar, ambos personajes históricos y héroes en su momento de la comunidad y convertidos con el tiempo en mitos y representación metafórica de la nación y la identidad local. En una palabra, tanto El cantar de Mío Cid como El poema de Dhar Oubarran son textos fundacionales de las dos culturas respectivas a las que pertenecen, la española y la rifeña. Un tema curioso que da para otro artículo de comparativa literaria con la finalidad de estudiar con precisión si tal similitud se debe a una dinámica de parentesco intercultural/transcultural o es pura coincidencia impuesta por los imperativos intrínsecos y universales de la cultura oral y popular mediterránea. En el apartado que sigue abordaré la dinámica de los moros y cristianos en El poema de Dhar Oubarran, pero desde una perspectiva comparada esta vez entroncada con la imagología y el discurso de la alteridad.

\section{España, lo español y la batalla de Annual vistos desde el Rif}

En la introducción de este breve estudio, he hecho hincapié en que la trascendencia de El poema de Dhar Oubarran tiene que ver principalmente con la proximidad emocional con que se vive la guerra, la verosimilitud narrativa con que se relatan sus acontecimientos y la apología entusiástica a la vez que trágica de la resistencia nacionalista y anticolonial. De estos tres aspectos deriva, por lo general, la visión local y marroquí tanto del transcurso de la contienda bélica como de la actuación de España en ella. Una visión que, aun teniendo todos los visos de ser sincera y real, no fue suficientemente considerada por parte española a la hora de leer y valorar el desastre de Annual y su significado, dado el desconocimiento de la lengua amazigh y la falta de una traducción al español del mismo poema hasta el día de hoy. Aunque el texto poético de El poema de Dhar Oubarran sigue siendo fragmentario e incompleto por disponer tan solo de 138 versos de los mil que se supone que tiene, la versión refleja la psicología local y la vivencia individual y colectiva de la ocupación española del Rif. Se articula el poema sobre tres puntos esenciales que detallamos en los subapartados que siguen.

\subsection{Discurso de alteridad y fata de lastre religioso y moral}

La lucha de moros y cristianos es algo intrínseco a la historia de España y la caracterizó desde la Edad Media hasta la expulsión de los moriscos en 1609. Una 
lucha que impregna en profundidad el imaginario español. La presencia española en los enclaves del Mediterráneo desde el siglo XIV y su implantación colonial en Marruecos a partir de 1912 trasladó la adversidad hispano-mora al espacio norteafricano. Hay al respecto una rica literatura popular y culta por la parte española, pero, de parte marroquí, El poema de Dhar Oubarran es, en el caso del Rif, uno de los pocos textos, cuando no el único, que trata ya en pleno siglo xx la atávica dualidad de moros y cristianos teniendo como trasfondo otro conflicto bélico como el de la batalla de Annual de 1921.

La dualidad moros vs cristianos / o moro vs cristiano no se plantea en este texto poético de Dhar Oubarran. Se sustituye por otra que, si bien refleja la misma conflictividad, adquiere significados distintos. La nueva dicotomía es la siguiente: rifeño/arumi o rifeños vs irumien, siendo el significado de arumi o irumien el de cristiano o cristianos. Arumi en singular es el más utilizado por el trovador en el poema para caracterizar al español. Se reitera casi una veintena de veces mientras que irumien, en plural, solamente aparece en tres ocasiones. El gentilicio español aparece dos veces, y lo mismo ocurre con el sustantivo España, utilizado como metonimia para referirse al español o a los españoles, en conformidad con el común proceder metonímico de todo el poema.

El gentilicio adjetivo arumi es el equivalente en muchos de los diccionarios en lengua amazigh de cristiano $^{32}$. Ibáñez Robledo y Sarrionandia recogen este mismo significado, pero lo extienden para abarcar otra sinonimia más amplia, en mi opinión más fundada y real: romano, católico, europeo, y añaden, aclarando más el vocablo, que se usa para «designar a todo el que no profesa su religión o su lengua. Su verdadero sentido es romano»33. Por cierto, en el poema se utiliza para referirse al español, pero sin referencia explícita a la religión porque, aquí, el término tiene sentido general que designa la alteridad hispánica como ajena y extraña, el mismo sentido general y abarcador que los griegos dieron a bárbaro/ bárbaros, esto es, a los extranjeros que no forman parte de la polis y también los españoles a moro/moros.

La dimensión religiosa no está ausente pero no se plantea desde la conflictividad y con exageración. Se invoca, no podía ser de otra manera en tiempos de guerra e invasión, al calificar al español como rkafer/infiel, el único atributo moral de naturaleza espiritual que se le imputa en todo el poema. Se corresponde por oposición en la parte marroquí a amjahed/imjahden, el combatiente o los combatientes por la fe, con que el poema describe a los guerreros rifeños. Esta palabra es la más utilizada y casi con igual frecuencia que arumi, teniendo igual sentido general y amplio, acaso ambiguo. Según Serhoual, amjahed significa, aparte de

32. Véase, por ejemplo, SABIR, Ahmed: Taknarit. Diccionario español-Amazigh, AmazighEspañol. s. i.: s.l.e., 2010, p. 273.

33. Ibánez Robledo, E. y Sarrionandia, P. H.: Diccionario Español-Rifeño, Rifeño-Español. Melilla/Barcelona: Bellaterra/Uned, 2007, pp. 152 y 47. 
combatiente por la fe, lo siguiente: guerrero, peleador y resistente ${ }^{34}$, es decir, como sinónimo de combatiente y luchador contra el enemigo. La atávica dicotomía entre dar el islam y dar el harb, muy peculiar de la historiografía marroquí y musulmana, no se plantea con rotundidad, sino que solo se insinúa en pocas palabras y sin desarrollo o repetición poética. En el verso 56 se subraya que tamsrant, es decir, el islam, metonimia o sinécdoque de los musulmanes rifeños, está de luto por las muertes y heridas provocadas por los bombardeos de los aviones y barcos españoles desde el aire y el mar. A tono con ello, se califica en el verso 118 a quienes luchan y mueren en la guerra como apóstoles, pero solo una vez se realiza en el texto. Por cierto, según los historiadores, Abd el-krim llamó, como es común en tierras del islam, a la Jihad, la guerra santa, contra el infiel e invasor porque era, y lo sigue siendo hasta el día de hoy, la manera pragmática y eficiente para confederar a más gente a favor de la causa, en este caso, a las tribus de la zona siempre enemistadas entre ellas por factores de diferente naturaleza. María Rosa de Madariaga da fe de que los líderes rifeños llamaron a la guerra santa y pidieron el apoyo de todos los marroquíes, incluso del sultán quien nunca correspondió ${ }^{35}$.

Otro calificativo de carácter cultural es el de bu-ijarwan, el de las ranas o el consumidor de las ranas, que se cita dos veces. El prefijo bu- en la lengua rifeña tiene carga peyorativa y, según indica con razón Serhoual, es portador de una connotación irónica " ${ }^{36}$, pero con la característica de ser, en mi opinión, un intento de caracterizar la acción o el comportamiento observado in situ y no en virtud del acervo arquetípico de prejuicios heredados del pasado o acumulados en la memoria colectiva. Por eso, muchos de los valores morales con que se establece la radiografía moral del español se alejan de la denigración, la caricatura y la blasfemia más siniestras y agresivas; suelen estar relacionados con la invasión, la cobardía, la violencia y la traición, pero son descritos en virtud de la actuación del español en el campo de la batalla o en su lucha contra los autóctonos, es decir, según se contempla la ocupación de los distintos pueblos y el bombardeo de los poblados. He aquí dos ejemplos de versos:

63 Se movilizó el arumi, a Monte Arruit ocupó, 64 llegó a Drius, por sus amigos ayudado entró, 65 ¡Oh, señora Tafersit!, en secreto se vendió, 66 se alegró el arumi y para sí solo la prefirió.

34. Serhoual, Mohammed: Dictionnaire tarifit-Français (Tesis doctoral inédita). Tetuán: Universidad Abdelmalek Essaãdi, 2001-2002, p. 237.

35. De Madariaga, María Rosa: España y el Rif. Crónica de una historia casi olvidada. Melilla: La Biblioteca de Melilla, 2000, pp. 467-470.

36. Serhoual, Mohammed: "L'épopée de Dhar Oubarran. Episode de la guerre du Rif (1921). Transcription, traduction et analyse de fragments». En: Forum d'Imerqane. Patrimoine en partage. Actes du 1 Festival des Cultures Immatérielles Méditerranéennes de Nador, op. cit. p. 125 
114 El avión se lanzó al cielo, echando humo,

115 en Iyarmawass, lo destruyó todo,

116 mató al niño Mohamed y su cuerpo frágil en dos lo partió.

Con un estilo informativo, directo y declarativo, el poeta popular reconoce, en el primer ejemplo, la ocupación del español de Monte Arruit pero la de Drius y Tafersit solo fue conseguida gracias a los traidores locales, sus amigos, que le ayudaron en secreto en su labor colonial, lo cual menoscaba su superioridad y pone en cuestión su valentía moral. Entretanto, en el segundo ejemplo, la violencia española es resaltada por los masivos bombardeos de los poblados y el destrozo del cuerpo de un tal Mohamed, metonimia de la suerte trágica que tuvo la indefensa población civil.

En tiempos de guerra y conflictos, el discurso de la alteridad es siempre negativo. No podía ser de otra manera. Este poema de Dhar Oubarran lo recoge, pero no con suficiente exageración o radicalismo. El español y España, pese a ser fuerza invasora, no se contemplan, al menos, en el texto como notredad absoluta; se insiste en la lucha sagrada contra el arumi invocando la jihad religiosa, pero sin denigración blasfematoria o racial. El español se describe en virtud de su actuación o comportamiento y no a través del tamiz de los estereotipos culturales y morales, como si éstos no existieran en el imaginario rifeño. Esta percepción poco conflictiva en un tiempo muy conflictivo es indicio de que no existía en el imaginario popular del Rif estereotipos fijos y esencialmente negativos con respecto al español, abstracción hecha del aspecto religioso. Es lo contrario del imaginario español en la misma época que, en su mayoría, se sustenta en lo más denigratorio, racial y paternalista en su valoración de los rifeños. En las canciones, la iconografía y la ficción literaria de la época, estos fueron sometidos, según analizó con detalle Martín Corrales, sin matiz o reserva a una caricaturización burlona, siniestra, dantesca, animal y faunesca para resaltar su primitivismo salvaje, su fanatismo religioso, su inferioridad humana, etc. Una percepción, en definitiva, "negativa y denigratoria»"37 "que incluía la salida a flote de las imágenes peyorativas acuñadas a lo largo de siglos de enfrentamientos entre cristianos y musulmanes en general y españoles y marroquíes en particular» ${ }^{38}$. He aquí, a guisa de ejemplo, un estribillo de una canción popular de la época, que cita María Rosa de Madariaga, con respecto a la figura de Abd el-krim:

37. Martín Corrales, Eloy: La imagen del magrebi en España. Una perspectiva histórica. siglos XVI-XX. Barcelona: Bellaterra, 2002, p. 147. Son muy interesantes, en este sentido, las últimas aportaciones de Gajate Bajo, María, Las campañas de Marruecos y la opinión pública: el ejemplo de Salamanca y su prensa (1909-1927). Madrid: Instituto Universitario General Gutiérrez Mellado, 2012;

38. Ibidem. 


\begin{abstract}
Abd el-Krim, cruel traidor,
¡Qué dolor, ay de mí!

Ante ti por mi amor

fui a implorar yo ahí.

Abd el-Krim, cruel traidor,

tu traición pagarás;

moro vil, por mi honor,

tú caerás, tú caerás ${ }^{39}$.
\end{abstract}

\title{
3.2. Aviación y brutalización bélica
}

La guerra, cualquier guerra, es inhumana y agresiva. Lo es aún más cuando es desproporcionada y desigual la relación de fuerza y poderío armamentístico y humano entre las dos partes en liza. Es el caso de la guerra colonial que España y su ejército africanista llevó a cabo en el Rif. El general Silvestre minusvaloró a Abd el-krim y a sus hombres, simples francotiradores quienes, si bien nunca tuvieron experiencias profesionales en acciones bélicas, tenían puntería, conocimiento del territorio y fe en su causa. El mencionado general imaginó que su ocupación del Rif sería un simple paseo triunfal, pero su descalabro en Annual -y la cacería y violencia de que fue objeto su ejército- dio lugar a uno de los desastres militares más llamativos de España y, sobre todo, a una reacción de castigo y tierra quemada contra los rifeños. Asistimos a una brutalización de la guerra sin precedentes, utilizándose sin miramiento y con agresividad los medios más sofisticados de destrucción masiva. A saber, la artillería y la aviación, que permitieron bombardear con bombas incendiaras y gases prohibidos, como la iperita, a la población civil en un intento de castigar y desmoralizar a toda costa a la resistencia local anticolonial. La teoría militar partía del postulado racial muy común a la sazón, que «sostenía que los pueblos que rechazaban la oportunidad que se les ofrecía de convertirse en gentes civilizadas merecían un trato igualmente incivilizado" ${ }^{40}$.

Los escritos españoles que describieron los avatares de las campañas de Annual y post-Annual silenciaron el tema del uso discriminado de las armas químicas en contra de la población civil y se limitaron a ponderar la violencia descomunal perpetrada por los rifeños y el calvario que sufrieron los soldados españoles.

39. De Madariaga, María Rosa. "La imagen de Abd-el-Krim El-Jattabi en la literatura de la época". En: Ramírez, Ángeles y López García, Bernabé (eds.). Antropología y antropólogos en Marruecos. Barcelona: Bellaterra, 2002, p. 218. Son muy interesantes, en este sentido, las últimas aportaciones sobre la presencia y representación de las campañas bélicas de Marruecos en la opinión pública, la prensa, la fotografía y demás textos gráficos, de Gajate Bajo, María, Las campañas de Marruecos y la opinión pública: el ejemplo de Salamanca y su prensa (1909-1927). Madrid: Instituto Universitario General Gutiérrez Mellado, 2012 y de Iglesias Amorín, Alfonso, "La evolución de la imagen de la guerra de Marruecos y su difusión en la opinión pública (1859-1927)", RUHM, Revista Universitaria de Historia Militar, vol. 8, 16, 2019, 104-131.

40. Balfour, Sebastian: op. cit., p. 163. 
No obstante, algunos sí que se hicieron eco del particular. Ignacio Hidalgo Cisneros reconoce en sus memorias tituladas Cambio de rumbo, tener el privilegio "de ser el primer aviador que tiró iperita desde un avión " ${ }^{41}$. Un periodista de El Heraldo describe en un relato escalofriante y con mucho detalle una razia de castigo y revancha que se efectuó sobre la cabila de Beni Bu Ifrur en que el autor se delecta viendo la devastación producida y remata su texto así: "Como en los días bíblicos de Sodoma, la cabila de Beni Bu Ifrur ya es sólo un montón de escombros» ${ }^{42}$. No pocos estudios de la historiografía militar abordaron con más detalle este tema de la aviación y su uso en la batalla de Annual así como en las diferentes campañas de España en Marruecos ${ }^{43}$.

En todo caso, los efectos producidos en la población civil nunca se describieron y debieron de ser horrorosos. Basándose en los documentos oficiales de la época así como en los testigos actuales que vivieron la época, varios historiadores como Sebatian Balfour y María Rosa de Madariaga ${ }^{44}$ y otros volvieron a aclarar los entresijos del uso de las armas químicas, el correspondiente genocidio perpetrado todavía no contabilizado en vidas humanas y, sobre todo, los efectos que tuvieron sobre la población civil, los animales y el entorno, amén de sus vivas y actuales secuelas, relacionadas en particular con la enorme cantidad de los enfermos de cáncer existente en la zona. Un documental hispano-marroquí titulado: Arrhash, de Tarik Al Idrissi y Javier Rada, volvió hace poco a ponerlo de relieve con testimonios de los últimos supervivientes de los bombardeos españoles, acompañados por comentarios de los historiadores.

En la narrativa española sobre la guerra de Marruecos, se destaca, entre otros aspectos, la inutilidad de la aviación en los días de Annual y en el abastecimiento de las posiciones sitiadas ${ }^{45}$. Por lo contrario, en El poema de Dhar Oubarran se insiste sobre el terrible miedo que daba a la población civil en unos de los versos, casi una quincena, más líricos en términos de expresión poética y de vivencia emocional y trágica de la guerra. Por cierto, no habla explícitamente de las armas químicas, ni describe los efectos materiales que estas producían, tampoco

41. De Madariaga, María Rosa: Los moros que trajo Franco... La intervención de tropas coloniales en la Guerra Civil. Barcelona: Martínez Roca, 2002, p. 64.

42. Ibid., p. 55

43. Véase Flores Alonso, E.: Guerra aérea sobre el Marruecos español (1913-1928). Madrid: Ministerio de Defensa, 1990; LÁzARo Ávila, C.: "Guerra aérea en el Rif: de Annual a Alhucemas (19211925)", Cuadernos de Aviación Histórica, 1, 2003, pp. 28-37; Abellán García Muñoz, J.: Aviones de la aviación militar española en la guerra de Marruecos (1913-1927). Madrid: Ministerio de Defensa, 2005; GuDIN DE LA LAMA, Enrique: «Una aviación en la frontera: la aeronáutica militar en la Guerra de Marruecos (1913-1927». En Frontera y fortificación. Madrid: Editorial Actas, 2017, pp. 405-424.

44. Balfour, Sebastian, op.cit. pp. 241-300; De Madariaga, María Rosa: Los moros que trajo Franco..., op. cit., pp.52-73.

45. Gudín DE LA LAMA, Enrique, "La aviación en la narrativa de la guerra del Rif», Novela bistórica e historia militar. Actas del II Congreso Internacional de Historia Militar (Universidad de La Rioja, 27-29 de marzo de 2015). Madrid: Ministerio de Defensa / Asociación Española de Historia Militar, 2016, pp. 408-422. 
da información sobre la cantidad de la población afectada pero sí el sentimiento de indefensión ante los bombardeos aéreos, y también desde el mar. El avión se vuelve otro protagonista y se subraya la letalidad de la harraka, término local con que se hacía referencia, siempre de manera metonímica, a las bombas incendiarias y tóxicas. Veámoslo con detalle.

La ocupación se contempla como invasión rápida e inesperada, una suerte de actuación que produce inquietud, perturba la sicología y pone fin a la vida, esta última simbolizada por las aguas frías que, en pleno verano canicular, hacen crecer las plantas, pero sin perder la misma fe en luchar contra el invasor de quien la voz poética está más convencida de que lo tendrá bajo su dominio:

35 ¡Oh, hijo mío, Monte Rahmam!, no estamos en paz, 36 tan fría está el agua que hace crecer las plantas.

37 Me invadieron las naciones, una pena me habita.

38 Juro que al de las ranas tendré en mis manos.

Luego se describe con cierta imparcialidad la actuación de los aviones y la mortalidad que causan en la población. Primero, se solicita la ayuda de dios invocándole a que haga desaparecer al avión de los montes de Ait Uriaguel, y, segundo, detalla los estragos letales que se producen entre los combatientes en los distintos lugares del Rif que fueron en su momento bombardeados desde el aire:

91 Apareció el avión girando como un cuervo,

92 ¡Oh dios mío! apártalo de los montes de Ait Urriaguel.

114 El avión se lanzó al cielo, echando humo,

115 en Iyarmawass, lo destruyó todo,

116 mató al niño Mohamed y su cuerpo frágil en dos lo partió.

El sentimiento de inquietud se ahonda más y se vuelve dramático e imposible de conllevar. Los versos que siguen expresan lo mucho que está apenada la voz poética por la muerte de Moh, el nombre de la víctima, causada por la bomba incendiara, la harraka, de la aviación española y, sobre todo, la intensidad de su compunción, abatimiento y angustia por no poder soportar físicamente su pérdida e informar, por consiguiente, a la esposa del muerto:

28 ¡Oh, Dios mío! ¿qué haré

29 con Khadouj, joh tío mío!, cuando la encuentre

30 y sobre el paradero de Moh me pregunte?

31 Moh, el combatiente, lo mató una bomba incendiaria.

32 ¡Oh, Dios mío! ¿qué haré

33 con mis negras pestañas llenas de lágrimas

34 que se caen, joh, madre mía!, sobre mis piernas? 
Mismo sentimiento se repite en iguales términos en otros versos, pero ahora haciendo hincapié en los daños que produce en los pueblos de Alhucemas, donde según cuentan los historiadores, los bombardeos fueron intensos y se lanzaban intensamente también desde la artillería de los barcos. La voz poética se lamenta preguntando sobre el paradero de la población, que tuvo que esconderse y abandonar sus casas huyendo de las bombas:

76 ¡Oh, Mulay Mohand!, más no podemos aguantar,

77 los aviones desde el cielo y las fragatas desde el mar.

78 ¡Oh, madre mía! ¡cuánto lloré!

79 Amakran, mi poblado, desierto quedó.

80 Apareció el avión dando vueltas,

81 vino a bombardear al gobernador de Ajdir.

82 Corazón mío ten paciencia, no llores más hijo mío,

83 aguanta igual que los montes a la niebla y a la nube.

84 ¡Oh casa esa, la que está en el monte!

85 ¿dónde está tu dueño, que ya desapareció?

86 ¿está enfermo o sano? dime ¿dónde se escondió?

La intensidad emocional con que son cantados estos versos por la voz poética se corresponde a la virulencia de los bombardeos y la mortalidad destructiva que causó en la población y los poblados. Una expresión tan sincera del calvario sufrido y de cuán intensa fue la destrucción provocada por la aviación y las bombas tóxicas e incendiarias. El uso de las armas químicas no acabó con la resistencia rifeña, tuvo que intervenir Francia con todo su ejército y así poder en complicidad con el poder del sultán acabar con la reciente República del Rif con la entrega de Abd el-krim y su inmediata deportación de por vida a La Reunión ${ }^{46}$. Annual fue el Guernica del Rif, un anticipo del otro Guernica, el español, del que siempre se habló mucho poniendo de relieve la atrocidad de la aviación de la Alemania nazi contra los habitantes indefensos de un pequeño de la Vasconia española. Ambivalencia de la historia que siempre se repite confundiendo víctima y victimario. Preguntado sobre qué pediría de España en el documental Arrhash, un superviviente del Guernica del Rif no quiso reivindicar nada en concepto de compensación, se rindió a la evidencia fatalista de la historia, sin demostrar odio ni animadversión al colonizador de ayer y al actual vecino de hoy porque tal vez tenía también en

46. Balfour lo afirma así con estas palabras: «La victoria final sobre dicha resistencia fue consecuencia, sobre todo, de la colaboración franco-española. El fracaso de la guerra química, que nunca estuvo a la altura de las expectativas españolas, se debió no sólo a su ingenuidad en cuanto a medidas tecnológicas o estratégicas, sino también a la minusvaloración de la capacidad del enemigo de seguir oponiendo resistencia", Abrazo mortal, op. cit. p. 300. 
mente las mismas actuaciones del ejército del recién Marruecos libre e independiente que volvió en 1958 a utilizar la misma lógica contra la población civil, otra memoria prohibida que sigue sin explorar.

3.3. De la apología de la resistencia al panegírico del militar español y de sus amigos locales

El poema de Dhar Oubarran es considerado como el poema de la resistencia por antonomasia contra la ocupación colonial española del Rif. Su componente épico consiste en cantar las proezas de los guerreros, exaltar su entusiasmo beligerante y enaltecer la osadía con que se enfrentan con sacrificio por la colectividad dando, por consecuencia, no podía ser de otra manera, una imagen negativa de los militares españoles tanto en su ocupación de los poblados como en su táctica militar, no sin poner en evidencia la facilidad con que son derrotados a través el uso de armas convencionales en los campos de batalla en que se desarrollaron las importantes acciones bélicas.

La lucha de moros y cristianos, referida en el primer párrafo, se contempla aquí muy claramente al convertir a Abd el-krim y al español en una dualidad disyuntiva que separa islam y enemigo infiel, aunque se plantea solamente una vez en el texto:

89 Abdelkrim es musulmán, que dios le ayude,

90 el español es enemigo, perdido está en el monte.

110 El arumi es infiel, en Annual cercado está,

111 monta sus tiendas y sus extremos bien ajusta.

El trovador anima a los combatientes a sacrificar su vida y canta sus proezas y, en especial, la temeridad demostrada en el campo de batalla, en conformidad con su tradición arraigada, la de ser luchadores por la fe en contra del invasor:

58 El arumi nos asalta, joh, madre mía! nos asalta,

59 mejor luchar a muerte que seguir viviendo.

60 Ataca el arumi y a Tizi Assa ocupa,

61 quiere preparar té con agua de Ouarma.

62 Luchad combatientes, es inútil la vida.

41 ¡Oh, Amar N'faquir!, atrapado en el alambre,

42 ¡Oh Amar n'Rmadani! gran combatiente,

43 luchasteis con pistolas y también con machetes,

44 vosotros los rifeños sois siempre combatientes,

El estilo apelativo hecho por el constante vocativo al combatiente se sustituye a veces con otro más telegráfico y narrativo. Consiste en describir la resistencia 
fuerte que los rifeños tuvieron que demostrar en los sitios en que entraba el español, el miedo dado a este último así como su humillación al obligarle a escaparse llevando solamente el abrigo que, para colmo de su deshonor, tenía que abandonar entrando en Melilla:

52 Se movilizó el arumi contra Annual y Monte Arruit, 53 ¡Oh, Mohamed ben Abd el-krim! el libre combatiente,

54 en la posición de Buymeyan fuegos se prendieron, 55 en la de Tmammacht gritos apenados se escucharon.

56 Huyendo el arumi, entre brazos su abrigo cogía, 57 por el camino lo tiró, cuando en Melilla entraba.

Siguiendo su estilo épico, el poeta popular insiste con frecuencia sobre la facilidad con que fueron derrotados y matados los soldados españoles que siempre se invocan como arumi o hablando en plural utilizando el pronombre personal «ellos» o irumien. Las metáforas de caries o carcoma de los huesos, utilizadas refiriéndose a las batallas de Dhar Oubarran y Tizzi Assa, reflejan el destino trágico que tuvieron los españoles al ser abatidos con facilidad por los combatientes, que solo utilizaban fusiles convencionales y, a veces, tan solo armas blancas como machetes y hoces. Una descripción que, si bien no implica una denigración moral o blasfematoria, encierra implícita ironía y pone de relieve la fuerte derrota sufrida por España en el Rif y la facilidad con que los rifeños llevaron la batalla al ser descrita como si fuera un paseo de recogida de plantas:

17 ¡Oh, Monte Abarrán! ¡Oh caries de los huesos!

18 donde estalló el cañón y se mordieron los caballos,

19 donde tirados como peces estaban los soldados

20 cuyos cascos quedaron como pimientos cocidos,

21 donde murió el gobernador y también el traductor.

22 ¡Oh, capitán Huelva! se te estrecha más el cerco,

23 ¿đónde están tus soldados?, todos están ya muertos.

24 Atacaron los Ait Urriaguel, niños y ancianos,

25 hicieron del de las ranas lo mismo que con las peces.

103 ¡Oh! Mulay Mohand, el gran combatiente,

104 atacó al arumi en Monte Abarrán,

105 unos llevaban balas, otros hoces.

106 Creyendo que a por plantas iban al río,

107 hicieron de los irumien botellas de tiro.

108 ¡Oh, Tizi Assa! lugar en que los combatientes

109 a los irumien cogieron como si fueran pollitos. 
En otro contexto, la voz poética insiste en el asedio que sufrió la posición de Tizzi Assa. El aislamiento que vivió esta localidad sin abastecimientos y, particularmente, sin agua, obligó al gobernador, llamado aquí en rifeño, Rcaid, a exprimir las patatas y beber su zumo o agua, otra metáfora del sufrimiento español, que se añade a las bajas entre los soldados, casi 8000 , la primera y única cifra que se menciona en el poema, y también a pedir más refuerzos a Málaga que apenas corresponde, dejando morir a los soldados en el monte Rahmam:

119 ¡Oh combatiente de mi alma! ¿saciaste tu sed o todavía?

120 El gobernador de Tizzi Assa exprime patatas,

121 por telégrafo a Málaga llama:

122 refuerzo necesito, todo se acaba,

123 ¿đónde están los ocho mil que de Málaga vinieron?

124 El último de ellos, en Rahman se cayó,

125 todo lo que había en Annual extraviado se quedó.

El poema resume con sutilidad y a través siempre de metáforas y metonimias lo que la historiografía ha descrito magistralmente: el terrible asedio del blocao sin agua, las altas bajas en el ejército español y la escasez de alimentos que solamente se hacían llegar tirándolos desde los aviones.

En no pocos de los escritos españoles sobre el transcurso de las campañas bélicas en el Rif hacen referencia con cierta curiosidad, acaso sorpresa, a la participación de la mujer en la guerra y la ayuda que aportaba a los hombres y, particularmente, la violencia que ella perpetraba contra los cuerpos muertos o heridos de los soldados. La imagen tradicional que se vinculaba con ella, la de ser burro de carga y odalisca sensual se trueca con la de ser una mujer fatal, pero en términos de violencia y salvajismo. En El poema de Dhar Oubarran que nos ocupa nos ofrece, por supuesto, una versión distinta celebrando la lucha anticolonial de la mujer y su participación indirecta en la resistencia. Es considerada a pie de igualdad con los hombres como una mujabida, combatiente por la fe, un término de índole espiritual que solamente era masculino. Se valoran asimismo los duros esfuerzos por ella desplegados en traer agua desde las fuentes en sus botijos que llevaba sobre su espalda, subir por acantilados, cuestas y montañas para suministrar alimentos de primera necesidad a los resistentes:

44 vosotros los rifeños sois siempre combatientes,

45 luchasteis con vuestras manos, lucharon también las mujeres,

46 con botijos de agua en su espalda, subían roquedales,

47 siempre iban cuesta arriba y cargadas.

A continuación, siempre en tono festivo, la voz poética da parabienes a la mujer rifeña por esta labor a favor y en apoyo de los guerreros y también, a buen seguro, por haber tenido a progenitores tan valientes que están luchando con sacrifico y valentía en el campo de batalla: 
48 Es como el azúcar de piñón, ornado con hilo,

49 ¡Oh, Fadma, la rifeña! buena progenitora es,

50 su cinturón de cuatro duros lo tiene bien merecido

51 igual que dar cuna al recién nacido.

El protagonista local que más recibe el desprecio y la denuncia panegírica es el que se llama "el partido de España" o "amigos pensionados" que estuvieron a favor de la intervención colonial en el Rif atraídos, como fue costumbre en esta época, por la política de atracción ejercida a este respecto por los españoles con la compra de voluntades y su nombramiento en altos cargos en la administración. El mismo Abd el-krim era al principio uno de ellos porque creyó en su momento en la labor modernizadora de España en la zona. Por cierto, muchos de los que eran amigos o colaboracionistas en un primer momento cambiaron de bando y se pusieron al lado de los nacionalistas cuando se desencadenó la guerra y se empezó a movilizar la población y las cabilas del Rif en nombre de la guerra santa contra el cristiano o el español. No obstante, otros fueron recalcitrantes y siguieron colaborando con el ejército español durante y después de Annual. Hay conocidos nombres al respecto como los que cita María Rosa de Madariaga que jugaron un papel muy considerable, amén del ejemplo del general Ameziane que participó incluso en la campaña de reconquista colonial y pacificación bélica posterior a Annual.

El poema de Dhar Oubarran no puede silenciar este aspecto, que fue determinante en el triunfo de España, tanto para la ocupación del territorio como para reprimir después a los nacionalistas que quedaron resistiendo por largo tiempo hasta 1926. Se citan al principio del poema dos de ellos, pero solamente con sus apodos denigratorios precedidos por el prefijo de cariz peyorativo e irónico bu-: bu-yawzan y bu-karkach, el primero, el del trigo cocido, haciendo referencia a sus orígenes humildes, y el otro, el de rostro multicolor, designación de su procedencia desahogada porque solo los ricos podían tener este tipo de vestimenta, sin olvidar por supuesto su naturaleza negativa, como metáfora de una persona impura en el físico, la piel y el atuendo pero también desde una perspectiva moral. En los versos finales del poema se habla directamente de este colaboracionismo local procolonial: se tilda de chivato al colaborador anónimo del pueblo por facilitar información al español, una moral traidora, muy denostada por parte de la comunidad: abandonar la familia sin la necesaria y obligada ayuda, emborracharse, venderse por dinero:

126 ¡Oh tía mía, tiene trigo el silo!

127 Tu marido va muy desvergonzado,

128 cuando no trabaja, al arumi ayuda,

129 multicolor su rostro, se fue sin dejar rastro,

130 teniendo a dorso solo pan y té que comía,

131 a su mujer dejó de mantener,

132 apostó por la botella de vino, moriría como un perro.

133 Nada ganaste, chivato del poblado,

134 preferiste el dinero a la cosecha del verano. 


\section{CONCLUSIONES}

El poema de Dhar Oubarran es hasta el momento el único texto poético que nos llega sobre la contienda de Annual de 1921; constituye el Mío Cid local del Rif siendo así una obra fundacional de la cultura local y de parte de su identidad. Pese a ser un texto producido y cantado en tiempos de conflicto bélico, lo español, que es sinónimo de arumi e invasor extranjero no se enfoca desde el prejuicio y la denigración blasfematoria de naturaleza religiosa y moral, sino tan solo en virtud de su actuación y comportamiento en el campo de batalla. Una percepción de la alteridad que es distinta de la detentada por la cultura popular de entonces en España con respecto al moro, que se arrojaba casi con automatismo a lo más salvaje y denigratorio de la humanidad, en sintonía con el acervo arquetípico negativo que se hereda de épocas remotas. El poema no aporta datos muy precisos sobre la batalla de Annual, pero sí describe la visión local de los acontecimientos y la vivencia del conflicto en clave individual y colectiva. En este sentido, la voz poética pone en evidencia tres aspectos: 1) la facilidad con que los combatientes rifeños pudieron triunfar abatiendo a los soldados españoles tan solo a base de armas convencionales, principalmente, fusiles, hoces y machetes; 2) la denigración del papel traidor desempeñado por los llamados "amigos de España", los colaboracionistas locales, en su apoyo a la ocupación colonial, y la correspondiente exaltación de la participación activa de la mujer en los campos de batalla aportando ayuda a la resistencia; y 3) la dimensión brutal y violenta de la aviación y, sobre todo, de su bombardeo de la población civil usando armas no convencionales y tóxicas. El sentimiento trágico con que la voz poética expresa la destrucción que producían los aviones es un signo ilustrativo del alcance negativo que tuvo entonces sobre la población. 